\title{
Research Paper Indigenous technical knowledge (ITK) and farmers willingness to practice- An economic study of arecanut peeling machines in Karnataka
}

See end of the paper for authors' affiliations

Correspondence to : B.N. PRADEEPA BABU Department of Agricultural Economics, University of Agricultural Sciences, BENGALURU (KARNATAKA) INDIA Email: pradeep4083@ rediffmail.com

Paper History :

Received : 25.04.2015

Revised : 28.06.2015;

Accepted : 27.07.2015
ABSTRACT : The Innovations are the outcome of survival strategies of the disadvantaged people in the risk prone and vulnerable regions. Over a period of time, a vast repository of knowledge and techniques, labeled as 'Indigenous Technologies and Knowledge' (ITKs) has been accumulated. It is based on experience, often tested over centuries of use, adapted to local culture, environment and dynamics. Indigenous knowledge is found to be socially desirable, economically affordable, sustainable and involve minimum risk to research users and widely believed to conserve resources. This study makes attempt to evaluate the socio-economic profiles of the grass root level innovation related to arecanut in Karnataka. It was found that, the cost of peeling in machine is much more economical than the manual method of peeling in arecanut. Further, about 80 of sample farmers are willing to buy or hire the arecanut-peeling machine in the study region. However, high cost of machines, lower efficiency followed by non-suitability of machine for all sizes of nuts were the major constraints faced by the farmers in mechanical method of arecanut processing.

KEY Words : Indigenous technical knowledge, Arecanut processing, Farmers willingness, Honey Bee Network, The National Innovation Foundation.

How To Cite This PAPer : Rajkumar, B.J., Prakash, T.N. and Babu, B.N. Pradeepa (2015). Indigenous technical knowledge (ITK) and farmers willingness to practice- An economic study of arecanut peeling machines in Karnataka. Internat. Res. J. Agric. Eco. \& Stat., 6 (2) : 307-316. 